\title{
West Nile Virus Infection and its Neurological Manifestations
}

\author{
Ken Madden, MD, PhD, Department of Neurology, Marshfield Clinic, Marshfield, Wisconsin
}

\begin{abstract}
The West Nile virus caused an epidemic of meningoencephalitis in Midwest North America during 2002. The peak incidence coincided with the highest activity period of mosquito vectors in affected states. This epidemic followed recent established trends, not only of increased central nervous system involvement by the virus, but also increased incidence of dramatic neuromuscular impairment. Two cases are presented which illustrate the most concerning types of neuromuscular sequelae, diffuse weakness leading to respiratory insufficiency, and the development of focal weakness similar to poliomyelitis. The epidemiology and clinical characteristics of West Nile virus infection are also reviewed. Concern is expressed regarding the possibility of epidemics in other Midwestern states during future seasons of increased mosquito activity.
\end{abstract}

\section{INTRODUCTION}

The first documented human infection of the West Nile virus occurred in the West Nile district of Uganda in 1937, and this virus has subsequently been implicated in recent encephalitis epidemics within Russia, Israel and Romania.1,2 It was the 1999 New York City outbreak within a large urban area, however, that stimulated concern over the virus among North Americans. ${ }^{3}$ Since that outbreak, the virus has spread coast to coast, with all but nine states within the continental United States reporting human infection. Surveillance immunoserological testing within endemic areas suggest that only $20 \%$ of individuals affected by the virus develop systemic symptoms, and less than $1 \%$ develop neurological manifestations. ${ }^{4}$ However, those that do develop nervous system involvement usually evolve a severe illness, with mortality rates of $12 \%$ to $14 \%$ and severe associated morbidity. The neurological manifestations are protean. Changes in mental status associated with meningitis or encephalitis are very common, but motor weakness is often the clinical indicator of West Nile virus as the causative agent.5,6 Two cases of West Nile virus infection at a tertiary care center are presented as examples of the unusual neuromuscular manifestations of this virus.

RECEIVED: JANUARY 22, 2003

REVISED AND ACCEPTED: MARCH 4, 2003

REPRINT REQUESTS:

Ken Madden, MD, PhD

Department of Neurosciences

Marshfield Clinic

1000 North Oak Avenue (4F2)

Marshfield, WI 54449

Telephone: $715-389-3225$

Fax: 715-387-5727

Email: madden.kenneth@marshfieldclinic.org
KEYWORDS:

West Nile virus; Encephalitis; Myelitis; Poliomyelitis 


\section{CASE REPORTS}

Case 1

A 79 year-old male resident of Illinois developed fever and malaise one week prior to and coincident with travel to upper Wisconsin. He initially sought medical attention in July at a regional urgent care facility, where he received ciprofloxin (500 mg twice daily) for possible urinary tract infection. He worsened on home antibiotic administration and returned for medical attention of persistent fever and the new development of mild confusion. While in the care facility, he had a generalized convulsion. Computed tomography revealed a $3 \times 1$ centimeter extra-axial frontal mass consistent with a meningioma, as well as mild generalized atrophy. He was intubated and treated with fosphenytoin, then transferred to a tertiary care center.

On arrival at the new center, his temperature was $101.6^{\circ} \mathrm{F}$, with normal pulse and blood pressures on multiple assessments. He had a supple neck and unremarkable cardiopulmonary exam. There were no evident skin lesions. On neurological assessment, he was agitated and mildly combative. He did not follow commands or effectively communicate non-verbally. Cranial nerve examination was unremarkable. He was mildly tremulous but had good power in all limbs as assessed by resistive movements. He withdrew appropriately from a painful stimulus in all limbs. Tendon reflexes were normal in the upper extremities, but not elicitable in the lower extremities. Plantar responses were flexor bilaterally.

Initial laboratory results included a leukocyte count of 9,600 with $89 \%$ neutrophils. Hemoglobin was $11.3 \mathrm{~g} / \mathrm{dl}$. Electrolytes were normal. Glucose was $146 \mathrm{mg} / \mathrm{dl}$. Transaminases were mildly elevated. Coagulation tests were normal. Initial chest $\mathrm{x}$-ray and electrocardiogram were normal. Blood and urine cultures were negative. Lumbar puncture was performed on arrival to the new facility and revealed $3 \mathrm{RBCs}$ and $958 \mathrm{WBCs}$ per $\mathrm{mm}^{3}$, total protein of $218 \mathrm{mg} / \mathrm{dl}$ and glucose of $59 \mathrm{mg} / \mathrm{dl}$. Aerobic and anaerobic cultures were negative. Cytology was negative. Lyme screen was negative. Polymerase chain reaction (PCR) for Herpes simplex virus was negative. Arbovirus IgM panel results included normal values for LaCrosse encephalitis and Eastern Equine encephalitis. Recent flavivirus infection was suggested, however, by IgM EIA optical density ratios (patient sera/ normal human sera control) of 7.51 for St. Louis encephalitis, and $>20$ for West Nile virus encephalitis (tests are presumptive positive when ratio exceeds 2.0). Plaque reduction neutralization test confirmed West Nile virus infection.

The patient was extubated after arrival at the tertiary care center, and his arterial blood gas after extubation was notable for a $\mathrm{pH}$ of 7.38 , a $\mathrm{pCO}^{2}$ of $41 \mathrm{mmHg}$, and a $\mathrm{pO}^{2}$ of 75 torr. Within 72 hours, however, he required reintubation after appreciable gradual diminishment of ventilatory effort and $\mathrm{CO}^{2}$ retention (maximum $68 \mathrm{mmHg}$ ). A clear pulmonary cause of respiratory insufficiency could not be demonstrated. Serial chest X-rays were notable for a small left pleural effusion and intermittent demonstration of a right infrahilar opacity felt most likely relatable to intermittent endobronchial obstruction. Sputum cultures were persistently negative. Bronchoscopy was ultimately performed on hospital day twelve and revealed endobronchial plugging by thick secretions. Coincident with the development of pulmonary insufficiency, the patient developed mild systemic weakness as well. This was symmetrical and involved both proximal and distal musculature.

By two weeks, he had begun to improve. He was extubated on his fourteenth hospital day. His systemic weakness required extensive rehabilitative efforts, but he was making slow steady gains with ambulation and self-cares by the time of his discharge to a local rehabilitative facility on his twenty-sixth hospital day. Cerebrospinal fluid had begun to normalize (19 leukocytes, protein 79) by the ninth day.

Case 2

A 49 year-old, long-haul truck driver presented to her local hospital in August complaining of fever and chills. She was placed on antibiotics for presumed pneumonitis and discharged after a short hospitalization. Six days after her initial admission, she was readmitted to a second hospital with fever of $103.2^{\circ} \mathrm{F}$, epigastric and lower abdominal pain, and four days of global headache. She had also just begun to notice weakness, numbness and pain of the right hand. Physical examination on that admission was notable for weakness of muscles of the right hand (no elaboration by admitting physician). Computed tomography of brain was unremarkable. Lumbar puncture revealed 225 leukocytes $/ \mathrm{mm}^{3}$ (90\% lymphocytes), glucose of $30 \mathrm{mg} / \mathrm{dl}$, and protein of $60 \mathrm{mg} / \mathrm{dl}$. Bacterial cultures were negative. Lyme screen was negative. The patient was transferred to a tertiary care center.

On arrival to the new center, physical examination was notable for substantial weakness of multiple muscles of the right upper extremity, including deltoid, biceps, triceps, wrist flexors, wrist extensors, finger flexors and finger extensors. Sensation was severely impaired in the right arm and deep tendon reflexes were absent. The sensorimotor exam of the remaining limbs was normal, as were deep tendon reflexes. Cognition, cranial nerves, coordination and gait were all normal. Serum creatine phosphokinase was normal. CSF analysis was repeated (7 days after initial lumbar puncture) and was notable for 106 leukocytes $/ \mathrm{mm}^{3}$ (90\% lymphocytes), glucose of $57 \mathrm{mg} / \mathrm{dl}$, and protein of $88 \mathrm{mg} / \mathrm{dl}$.

Bacterial, fungal, and acid-fast bacilli stains and cultures were negative. Viral cultures were negative. Cytology was negative. PCR for Herpes simplex virus was negative. Antibody assays for rubeola, mumps and varicella antibodies were negative. Arbovirus IgM panel results included normal values for LaCrosse encephalitis and Eastern Equine encephalitis, but positive IgM EIA optical density ratios of 4.4 for St. Louis encephalitis, and $>20$ for West Nile virus encephalitis. Plaque reduction neutralization test confirmed West Nile virus infection.

146 CM\&R 2003 : 1 (April) Madden


Further evaluation of the patient's right arm weakness included magnetic resonance imaging of brain and cervical spine. The cerebral study was unremarkable. The cervical imaging revealed degenerative changes causing central canal narrowing and foraminal compromise affecting the right fifth cervical root. These abnormalities did not appear significant enough to cause the sensorimotor impairment of the right arm. Electromyography and nerve conduction testing of the limb were therefore performed. Nerve conductions were generally remarkable only for decreased motor unit amplitudes and absent F-waves (median and ulnar). Electromyography of multiple distal and proximal muscles of the right arm revealed increased insertional activity and decreased recruitment in all muscles, but normal waveforms in paraspinal muscles. There were no fibrillations. The electromyographic impression was that the findings were most consistent with a preganglionic neuropathology involving cervical spinal cord segments C5 to T1. Clinically, she improved during her hospitalization, with normalization of her mental status and resolution of headache and fever. She remained with pronounced weakness of the right arm at the time of discharge.

\section{DISCUSSION}

\section{Viral epidemiology}

The West Nile virus is a single-stranded RNA virus of the genus Flavivirus, which also includes the viruses responsible for St. Louis encephalitis, Japanese encephalitis and Murray Valley encephalitis. The mechanism by which the West Nile virus was introduced into the Western hemisphere remains unknown, but its transmission cycle is now well understood. Wild birds, particularly songbirds, serve as the primary amplification hosts in nature, though infections also occur in horses and other avian species. Geographical spread of the virus in North America has occurred along the migratory pathways of the usual bird hosts. Regional infections of birds within the Corvidae family (crows, jays and magpies) have particular importance because the severe illness that develops in these species leads to high avian mortality, therefore serving as a sentinel of the virus within the locality. ${ }^{7}$ The virus is transmitted from bird to human hosts through the bite of mosquitoes, usually those of the Culex genus. Mammals do not generate viremia of a magnitude that allows further transmission of the virus. ${ }^{8}$ (The interested reader is referred to excellent discussions of these topics in the preceding edition of this journal). ${ }^{9}, 10$

In 2002, the state harboring the most human cases of West Nile virus infection was Illinois, with 836 cases and 56 deaths. Infections began in late summer and peaked in September. Because of the rapid immunity to recurrent infection that develops in birds, the incidence may more likely increase in neighboring states than in Illinois during future seasonal outbreaks.
Clinical manifestations of West Nile virus infection Typically, flavivirus infection in humans is manifested by three clinical syndromes: fever/arthralgia/rash, viral hemorrhagic fever, and neurological disease. ${ }^{11}$ The West Nile virus has developed a particularly neurotropic invasion pattern, and this may have recently evolved. Prior to 1996, few patients afflicted with the virus suffered neurological manifestations, and the severe and often fatal encephalitides that have been associated with subsequent outbreaks have been surprising. ${ }^{2}$ Inoculated virus is thought to seed the endoplasmic reticulum where the virus replicates, ultimately resulting in secondary viremia that penetrates the central nervous system. ${ }^{12}$ Clinical symptoms develop approximately two days after the peak of viremia. The virulence and neuroinvasiveness of the virus likely relates to the level and duration of viremia within infected individuals, as well as, the relative preservation of the cerebrovascular endothelium. ${ }^{13}$ Some researches speculate that susceptibility may be genetically determined as well. ${ }^{14}$

Mechanisms of viral entry into, and diffusion through, components of the nervous system are not currently understood, but may involve the West Nile virus envelope E protein that mediates cell attachment. ${ }^{15}$ After the virus is established in the central nervous system, its pathophysiology is based on neuronal proliferation, cytotoxic immune responses, perivascular inflammation, and microglial nodule formation. ${ }^{12,16,17}$ In fatal cases, the most common inflammatory focus is brainstem, but thalamus, cerebellum, and cerebral cortex are also involved. ${ }^{18}$ In contrast to other arboviral infections, the inflammatory infiltrate is minimal and there is no vasculitis. ${ }^{16}$ Until recently, autopsies of fatal cases have not included sectioning of spinal cord, and neuropathology of this portion of the central nervous system had been lacking.

Most West Nile virus infections do not result in clinical symptoms, ${ }^{4}$ though many cases of mild disease may go unreported. "West Nile fever" is one such milder expression of the disease causing fever, malaise, and arthralgias that usually resolve within a week (table 1). Half of such patients may develop a roseolar or macropapular rash or generalized lymphadenopathy, but these also commonly resolve without significant sequelae. The fatality rate for patients with these mild cases of West Nile virus infection is quite low $(<1 \%)$.

During the major epidemics since 1996, several days of fever progressed to the syndromes typical for meningoencephalitis in a much higher percentage of patients.

Approximately $60 \%$ of such individuals had alteration of mental status that indicated encephalitis, and up to $13 \%$ of infections progressed to coma. ${ }^{19}$ In contrast to other viral encephalidities, seizures were uncommon. ${ }^{1,20}$ In addition to meningitis and encephalitis, other cerebral manifestations of West Nile virus infection included ataxia, extrapyramidal syndromes, and cranial neuropathies ${ }^{9}$ (table 2 ). 
Table 1. Systemic symptoms associated with West Nile virus infection (in descending order of frequency, with ranges as reported in nine major epidemics). ${ }^{34}$

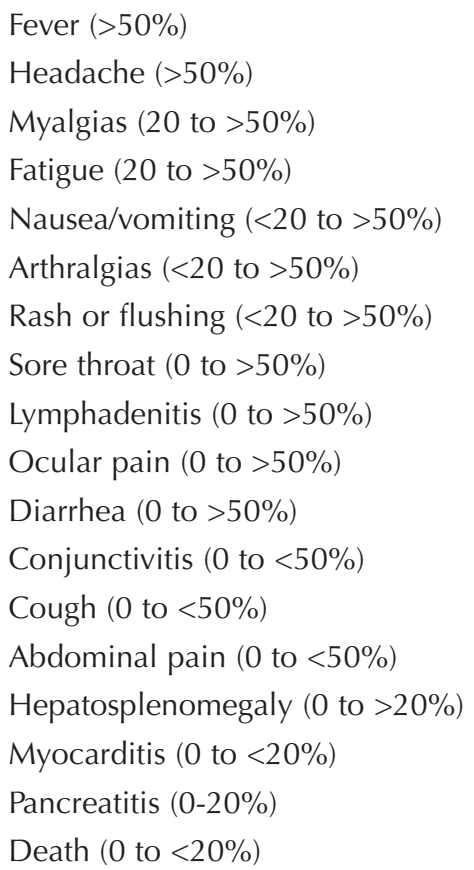

Table 2. Neurological manifestations of recent encephalitis epidemics, in descending order of incidence. $6,13,20,35$

Confusion (40-90\%)

Meningismus and headache (40-90\%)

Somnolence (40-70\%)

Diffuse weakness or asthenia (40-60\%)

Axonal polyneuropathy (30-50\%)

Photophobia (30-50\%)

Respiratory failure (10-25\%)

Coma (10-15\%)

Extrapyramidal syndromes (0-10\%)

Anterior myelitis (0-10\%)

Ataxia $(0-10 \%)$

Polyradiculitis (0-10\%)

Seizure $(0-10 \%)$

Tremor $(0-10 \%)$

Cranial neuropathies (0-10\%)

Hypertonicity and hyperreflexia (0-10\%)

Optic neuritis (0-10\%)

Neuromuscular manifestations of West Nile virus infection Coincident with the substantially increased incidence of meningoencephalitic involvement in recent epidemics has been frequent severe neuromuscular impairment in afflicted patients. In the Romania and Russia epidemics, muscle weakness was estimated to have occurred in $15 \%$ to $20 \%$ of hospitalized patients, ${ }^{20,21}$ but during the North American epidemics this has occurred in approximately $50 \%$ of patients. Weakness can be manifested by diffuse limb paresis (often with a proximal predominance), asymmetric flaccid paralysis, or respiratory failure. Deep tendon reflexes are typically depressed in the involved limbs. Most patients that recovered from the acute illness ultimately experienced improvement of neuromuscular symptoms as well, though prolonged rehabilitation efforts were often necessary. ${ }^{22}$

Within the last few months, autopsy evidence has emerged that implicates spinal cord involvement as the underlying cause of the muscle weakness associated with West Nile virus infection in some patients. The first report of asymmetric flaccid paralysis in conjunction with West Nile virus infection was in 1979, but no pathological data from this patient was obtained. ${ }^{23}$ This phenomenon was then largely unreported until instances began surfacing with the North American epidemics. The initial cases of severe weakness with depressed tendon reflexes were attributed to GuillainBarre' syndrome. ${ }^{24,25}$ During the 2002 outbreaks in the southwestern United States, a series of patients were encountered that had areflexic flaccid paralysis with preserved sensation. ${ }^{26,27}$ Electrophysiologic studies were notable for markedly decreased motor responses in the involved limbs, with asymmetric muscle denervation, but without evidence of demyelination, myopathy, or sensory conduction disturbances. The electrophysiological evidence was not consistent with Guillain-Barre', and the possibility of anterior myelitis complicating West Nile virus infection was reported to the U.S. Center for Disease Control and Prevention. Additional patients displayed similar clinical syndromes in the same region. Eventually three patients were autopsied after dying from pulmonary complications.

Pathological inspection of the spinal cord in these patients revealed gliosis and neuronal loss in the ventral grey matter, with extensive perivascular cuffing by inflammatory cells. Inflammatory cells also surrounded dying anterior horn neurons. Notably, these findings were similar to necropsy findings of spinal cord in animals infected with the West Nile virus. ${ }^{28,29}$ These data seem to suggest a predilection of this virus for the anterior horn cell and the production of a clinical state similar to that of acute poliomyelitis.

The clinical case presentations within this report include one patient whose primary neuromuscular manifestation of West Nile virus infection was respiratory failure. No pulmonary cause of his ventilator dependency was determined. His degree of mental status impairment did not appear profound enough to cause central respiratory failure. Other neurological causes of respiratory insufficiency such as critical care neuropathy or myopathy were not excluded by electrophysiological testing, but he did not display the other clinical manifestations of widespread neuropathy/myopathy that are usually associated with these conditions. The second patient in this report developed the clinical symptoms (asymmetrical, areflexic, flaccid paralysis) and electrophysiological findings typical for poliomyelitis involving the cervical spinal cord. Her clinical history and examination was not consistent with Guillain-Barre', nor did the electrophysiology suggest such. Brachial plexitis could be an alternative etiology for her clinical presentation, but the electrophysiol- 
ogy evidence also conflicted with this diagnosis. These cases therefore illustrate the type of severe neuromuscular involvement that can occur with West Nile virus infection. Both respiratory failure and the expression of a poliomyelitis-like syndrome are associated with higher incidence of fatal outcome of the infection, 30 though both patients reported here survived.

\section{Diagnosis and treatment of West Nile virus infection} Unusual laboratory data in infected patients is typically nonspecific. A modest leukocytosis is often present, but leukocyte counts have been normal in over $50 \%$ of patients. Computed tomography of brain has rarely revealed specific pathology. Magnetic resonance imaging has occasionally revealed leptomeningeal enhancement or periventricular inflammatory changes, but up to $70 \%$ of such images have been unremarkable. ${ }^{6}$ Cerebrospinal fluid analysis often discloses a mild lymphocyte predominant leukocytosis, but counts rarely exceed 100 cells/microliter. Spinal fluid glucose is normal and only modest elevation of protein occurs (rarely exceeding $100 \mathrm{mg} / \mathrm{dl}$ ). Because of the low levels of viremia associated with human West Nile virus infection, neither virus culture nor PCR are sensitive for its detection.

Specific laboratory testing for West Nile virus infection can be accomplished with IgM antibody capture enzyme-linked immunosorbent assay (EIA) in both serum and spinal fluid. Over $95 \%$ of those suspected of West Nile virus infection during the New York epidemic had demonstrable antibody. ${ }^{30}$ The EIA assay does cross-react with other flaviviruses, though quantitatively less so. ${ }^{31}$ Detection of antibody in the spinal fluid is diagnostic of central nervous system involvement, as the IgM antibody does not cross the blood-brain barrier. Specific testing is available through state health departments, and identified infection is reportable to infectious disease registries. The reporting of even a single case to state agencies may have substantial implications for regional public health policies. ${ }^{30}$

Thus far, no treatment has been proven effective for West Nile virus infection. Patient care largely involves supportive measures, including the usual prophylactic measures for complications of immobility and depressed alertness. Acyclovir for treatment of Herpes simplex encephalitis could certainly be considered until this possibility is excluded by specific testing, or the West Nile virus is positively implicated. Specific treatment for West Nile virus infection has been attempted with intravenous immunoglobulin $^{32}$ and oral ribavirin, ${ }^{33}$ but neither treatment has established efficacy. The U.S. Food and Drug Administration has approved one clinical trial to explore the efficacy of interferon compared to placebo, and it is now accruing patients.

\section{SUMMARY}

The West Nile virus has caused epidemics of increasing magnitude in North American since its arrival in 1999. Coincident with increased infection rates, a greater incidence of severe meningoencephalitic illness and neuromuscular impairment related to the virus has evolved. The respi- ratory failure or poliomyelitis syndromes that occur lead to high morbidity and mortality rates. Following the large outbreak of illness in Illinois during 2002, similar epidemics may occur in neighboring states during future seasons of high mosquito activity. Usual preventive measures against mosquito bites, such as the use of repellants, and mosquito control measures, should be a high priority in these susceptible regions. ${ }^{10,30}$ Health care workers need to be vigilant toward the possibility of West Nile virus infection in patients encountered with typical symptoms, both for patient care and public health concerns.

\section{REFERENCES}

1. Chowers MY, Lang R, Nassar F, Ben-David D, Giladi M, Rubinshtein E, Itzhaki A, Mishal J, Siegman-Igra Y, Kitzes R, Pick N, Landau Z, Wolf D, Bin H, Mendelson E, Pitlik $\mathrm{SD}$, Weinberger M. Clinical characteristics of the West Nile fever outbreak, Israel, 2000. Emerg Infect Dis 2001;7:675678.

2. Hayes CG. West Nile virus: Uganda, 1937, to New York City, 1999. Ann N Y Acad Sci 2001;951:25-37.

3. O'Hara JA 3rd. West Nile virus: success of public health response underlines failure of the system. J Urban Health 2001;78:392-395.

4. Mostashari F, Bunning ML, Kitsutani PT, Singer DA, Nash D, Cooper MJ, Katz N, Liljebjelke KA, Biggerstaff BJ, Fine AD, Layton MC, Mullin SM, Johnson AJ, Martin DA, Hayes EB, Campbell GL. Epidemic West Nile encephalitis, New York, 1999: results of a household-based seroepidemiological survey. Lancet 2001;358:261-264.

5. Weiss D, Carr D, Kellachan J, Tan C, Phillips M, Bresnitz E, Layton M; West Nile Virus Outbreak Response Working Group. Clinical findings of West Nile virus infection in hospitalized patients, New York and New Jersey, 2000. Emerg Infect Dis 2001;7:654-658.

6. Nash D, Mostashari F, Fine A, Miller J, O’Leary D, Murray K, Huang A, Rosenberg A, Greenberg A, Sherman M, Wong S, Layton M; 1999 West Nile Outbreak Response Working Group. The outbreak of West Nile virus infection in the New York City area in 1999. N Engl J Med 2001;344:1807-1814.

7. Eidson M, Komar N, Sorhage F, Nelson R, Talbot T, Mostashari F, McLean R; West Nile Virus Avian Mortality Surveillance Group. Crow deaths as a sentinel surveillance system for West Nile virus in the northeastern United States, 1999. Emerg Infect Dis 2001;7:615-620.

8. Komar N. West Nile viral encephalitis. Rev Sci Tech 2000;19:166-176

9. Reed KD, Meece JK, Henkel JS, Shukla SK. Birds, migration, and emerging zoonoses: West Nile virus, Lyme disease, Influenza A and enteropathogens. Clin Med Res 2003;1:5-12.

10. Meece JK, Henkel JS, Glaser L, Reed KD. Mosquito surveillance for West Nile virus in southeastern Wisconsin- 2002. Clin Med Res 2003;1:37-42.

11. Solomon T, Mallewa M. Dengue and other emerging flaviviruses. J Infect 2001;42:104-115.

12. Deubel V, Fiette L, Gounon P, Drouet MT, Khun H, Huerre M, Banet C, Malkinson M, Despres P. Variations in biological features of West Nile viruses. Ann NY Acad Sci 2001;951:195-206.

13. Campbell GL, Marfin AA, Lanciotti RS, Gubler DJ. West Nile virus. Lancet Infect Dis 2002;2:519-529.

14. Perelygin AA, Scherbik SV, Zhulin IB, Stockman BM, Li Y, Brinton MA. Positional cloning of the murine flavivirus resistance gene. Proc Natl Acad Sci USA 2002;99:93229327. 
15. Roehrig JT, Staudinger LA, Hunt AR, Mathews JH, Blair CD. Antibody prophylaxis and therapy for flavivirus encephalitis infections. Ann N Y Acad Sci 2001;951:286-297.

16. Sampson BA, Armbrustmacher V. West Nile encephalitis: the neuropathology of four fatalities. Ann N Y Acad Sci 2001;951:172-178.

17. Shieh WJ, Guarner J, Layton M, Fine A, Miller J, Nash D, Campbell GL, Roehrig JT, Gubler DJ, Zaki SR. The role of pathology in an investigation of an outbreak of West Nile encephalitis in New York, 1999. Emerg Infect Dis 2000;6:370-372.

18. Sampson BA, Ambrosi C, Charlot A, Reiber K, Veress JF, Armbrustmacher V. The pathology of human West Nile Virus infection. Hum Pathol 2000;31:527-531.

19. Tsai TF, Popovici F, Cernescu C, Campbell GL, Nedelcu NI. West Nile encephalitis epidemic in southeastern Romania. Lancet 1998;352:767-771.

20. Ceausu E, Erscoiu S, Calistru P, Ispas D, Dorobat O, Homos M, Barbulescu C, Cojocaru I, Simion CV, Cristea C, Oprea C, Dumitrescu C, Duiculescu D, Marcu I, Mociornita C, Stoicev T, Zolotusca I, Calomfirescu C, Rusu R, Hodrea R, Geamai $\mathrm{S}$, Paun L. Clinical manifestations in the West Nile virus outbreak. Rom J Virol 1997;48:3-11.

21. Platonov AE. West Nile encephalitis in Russia 1999-2001: were we ready? Are we ready? Ann N Y Acad Sci 2001;951:102116.

22. Ohry A, Karpin H, Yoeli D, Lazari A, Lerman Y. West Nile Virus Myelitis. Spinal Cord 2001;39:662-663.

23. Gadoth N, Weitzman S, Lehmann EE. Acute anterior myelitis complicating West Nile fever. Arch Neurol 1979;36:172-173.

24. Asnis DS, Conetta R, Waldman G, Teixeira AA. The West Nile virus encephalitis outbreak in the United States (1999-2000): from Flushing, New York, to beyond its borders. Ann N Y Acad Sci 2001;951:161-171.

25. Ahmed S, Libman R, Wesson K, Ahmed F, Einberg K. Guillain-Barre' syndrome: An unusual presentation of West Nile virus infection. Neurology 2000;55:144-146.

26. Glass JD, Samuels O, Rich MM. Poliomyelitis due to West Nile virus. N Engl J Med 2002;347:1280-1281.

27. Leis AA, Fratkin J, Stokic DS, Harrington T, Webb RM, Slavinski SA. West Nile poliomyelitis. Lancet Infect Dis 2003;3:9-10.

28. Manuelidis EE. Neuropathology of experimental West Nile virus infections in monkeys. J Neuropathol Exp Neurol 1956; $15: 448-460$.

29. Cantile C, Del Piero F, Di Guardo G, Arispici M. Pathologic and immunohistochemical findings in naturally occuring West Nile virus infection in horses. Vet Pathol 2001;38:414421.

30. Petersen LR, Marfin AA. West Nile virus: a primer for the clinician. Ann Intern Med 2002;137:173-179.

31. Martin DA, Biggerstaff BJ, Allen B, Johnson AJ, Lanciotti RS, Roehrig JT. Use of immunoglobulin $m$ cross-reactions in differential diagnosis of human flaviviral encephalitis infections in the United States. Clin Diagn Lab Immunol 2002;9:544549.

32. Shimoni Z, Niven MJ, Pitlick S, Bulvik S. Treatment of West Nile virus encephalitis with intravenous immunoglobulin. Emerg Infect Dis 2001;7:759.

33. Spiegel R, Miron D, Gavriel H, Horovitz Y. West Nile virus meningoencephalitis complicated by motor aphasia in Hodgkin's lymphoma. Arch Dis Child 2002;86:441-442.

34. Hubalek Z. Comparative symptomatology of West Nile fever. Lancet 2001;358:254-255.

35. Klein C, Kimiagar I, Pollak L, Gandelman-Marton R, Itzhaki A, Milo R, Rabey JM. Neurological features of West Nile virus infection during the 2000 outbreak in a regional hospital in Israel. J Neurol Sci 2002;200:63-66. 